\title{
Desconstruindo Discursos de Diferença na Escola
}

Walace Rodrigues'

'Universidade Federal do Tocantins (UFT), Araguaína/TO - Brasil

RESUMO - Desconstruindo Discursos de Diferença na Escola. Este artigo busca compreender algumas representações artísticas de homens negros nas artes ocidentais (do século XV ao XIX). A análise aqui se volta para a área da educação, pretendendo-se compreender como o discurso da diferença é construído, também, através da arte. Os exemplos de obras artísticas neste escrito são de: Dürer (1471-1528), Rubens (1577-1640), Debret (1768-1848) e Rugendas (1802-1858). Todos esses são artistas importantes dentro da história da arte ocidental. Pretende-se, através das referidas obras analisadas, um entendimento das imagens do homem negro representado em estilo de retrato. Esses trabalhos de arte são Cabeça de um Negro, de Albrecht Dürer; Cabeça de um Homem negro, de Peter Paul Rubens; Diferentes Nações Negras, Jean-Baptiste Debret; e Moçambique, de Johann Moritz Rugendas.

Palavras-chave: Discurso. Representação. Artes Visuais Ocidentais. Homem Negro. Educação.

ABSTRACT - Deconstructing Discourses of Difference at School. This article seeks to better understand some artistic representations of black men in the Western arts (from the 15th the 19th century). The analysis refers to the education field, aiming to understand how the discourse of difference is constructed, also, through art. Examples of artistic works in this paper are: Dürer (1471-1528), Rubens (1577-1640), Debret (1768-1848) and Rugendas (1802-1858). These are all important artists within the history of Western art. It is intended, through the works analyzed, to understand the images of the black man represented in portrait style. These artworks are Albrecht Dürer's Head of a Negro; Head of a Black Man, by Peter Paul Rubens; Different Black Nations, Jean-Baptiste Debret; and Mozambique, by Johann Moritz Rugendas.

Keywords: Discourse. Representation. Western Visual Arts. Black Man. Education.

Educação \& Realidade, Porto Alegre, v. 42, n. 2, p. 687-706, abr./jun. 2017. 687 http://dx.doi.org/10.1590/2175-623657231 
Desconstruindo Discursos de Diferença na Escola

\section{Introdução}

Representações não são simples imitações artísticas da natureza, mas sim a interpretação ativa e criativa de um artista e despertam variadas leituras dos seus vários expectadores. Elas sempre fazem referências aos repertórios de imagens, memórias, sonhos, desejos, aprendizados, etc., de tais espectadores.

Encarando o estranhamento dos artistas em relação aos negros ${ }^{1}$ a antropóloga Mirela Berger (2007) diz que são conceitos como estranhamento e relativismo que nos ajudam a recontextualizar os sentidos da diferença, sempre considerando a diferença como a grande riqueza dos seres humanos, pois somente nos conhecemos através das diferenças, através da contraposição entre nós e os outros seres humanos. Assim, conhecer o diferente leva a conhecer-nos a nós mesmos.

Portanto, este artigo deseja mostrar representações de homens negros dentro da história da arte ocidental, com foco nas obras de artistas visuais que nos deixaram ver, em seus trabalhos, uma variedade de rostos de negros, sejam pintados, desenhados, em aquarela etc. Os artistas escolhidos para revelar essas faces negras foram o alemão Dürer (1471-1528), o flamengo Rubens (1577-1640), o francês Debret (17681848) e o alemão Rugendas (1802-1858). Todos muito conhecidos do público habituado com artes da pintura, gravuras, desenho e aquarela.

Ainda, no ambiente educacional, devemos explicitar como o discurso arquitetado através de representações imagéticas do homem negro é construído. Além de esse discurso poder nos servir para um entendimento de que as manifestações ideológicas de diferença também podem ser desconstruídas e desaprendidas na escola.

\section{Discursos Imagéticos e seu Poder Educacional}

Podem dizer que é muito complicado falar de representação dentro do campo das artes visuais, pois, como nos diz Stuart Hall (2009), representação é a forma na qual o significado é atribuído às coisas descritas (mímica, verbal, visual, entre muitas outras formas). Portanto, representação não tem, e jamais terá, um significado fixo, já que está aberta a múltiplas interpretações. Assim sendo, significar sofre as influências da interpretação individual e de como cada informação é representada. Compreendemos, então, que o processo de representar tudo que nos rodeia é um contínuo e vivo mecanismo de criação de significações.

Assim, as obras de Albrecht Dürer, Peter Paul Rubens, Jean-Baptiste Debret e Johann Moritz Rugendas, que retrataram rostos de homens negros, colocaram-se como abrangentes e poderosos meios de circulação de significações acerca destes homens. Lembramos que essas imagens foram exibidas ao público de sua época e tidas como retratos de verdades sobre os negros, tal era o poder da arte!

Claro que os rostos dos homens negros que foram objeto deste artigo são faces de homens escravizados, privados de liberdade, priva-

688 Educação \& Realidade, Porto Alegre, v. 42, n. 2, p. 687-706, abr./jun. 2017. 
dos de escolhas. No entanto, toda a desumanidade da escravidão não foi suficiente para apagar seus rostos. Lembramos, também, que nossos rostos marcam nossas identidades, apresentando-nos ao mundo; eles estampam nossos documentos de identificação, chegando, portanto, antes de nós mesmos.

Nas faces dos homens representados não vemos sorrisos, já que não há porque sorrir sem liberdade. No entanto, a coragem dos artistas em tê-los como modelos (os negros eram tidos como indignos de serem pintados) soma-se à bravura desses negros em se deixarem representar. Tais pessoas passaram pela história sem receber nomes, porém, nos deixaram suas belas imagens como testemunhas de suas existências sofridas e de presenças únicas no mundo.

Começamos nossa análise pela obra Cabeça de um Negro (Figura 1), acreditada ser de 1508, do conhecido gravurista alemão Albrecht Dürer. Dürer ficou conhecido por fazer primorosas gravuras rebuscadas e detalhistas. Aqui ele faz um desenho, a carvão vegetal, da cabeça de um negro. Tal homem mostra um olhar perdido. Sabemos pouco sobre este trabalho de Dürer. Tal estudo deve ter sido executado com a ajuda de um modelo masculino, coisa usual à época de Dürer. As pouquíssimas informações sobre esse trabalho deixam ver a irrelevância intelectual colocada sobre obras que retrataram homens negros no século XV. No entanto, esse desenho demonstra certo interesse de Dürer pela representação dos mais variados tipos humanos.

Figura 1 - Dois Desenhos de Dürer: Cabeça de um Negro, 1508 (?), e Katharina, 1521

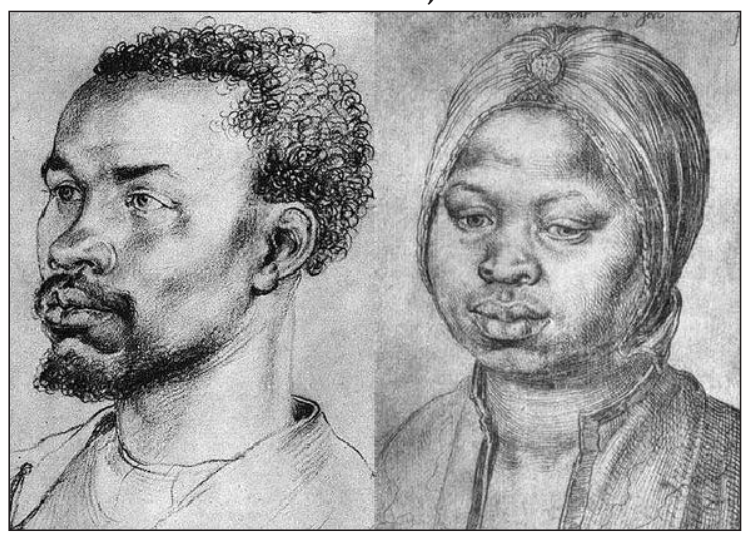

Fonte: Spicer (2013).

No desenho Katharina, diferentemente de Cabeça de um Negro, Dürer nomeia sua modelo e deixa-nos ver sua religião (muçulmana). $\mathrm{O}$ homem negro representado pelo mesmo artista não tem identificações para além de um ano (1508). Ainda, sabemos que o desenho Katharina foi executado na Bélgica, em Antuérpia, em 1521. Sabemos que ela foi a escrava de um representante de Portugal, chamado João Brandão. Esse senhor Brandão era um dos conhecidos patronos de Dürer. Uma informação no desenho nos deixa saber que Katharina tinha 20 anos.

Educação \& Realidade, Porto Alegre, v. 42, n. 2, p. 687-706, abr./jun. 2017. 
Desconstruindo Discursos de Diferença na Escola

Podemos notar, também, que os dois desenhos deixam ver olhares perdidos, sem o menor sinal de alegria, mas de obrigação. Voltamos a lembrar que o homem negro não teve nem a possibilidade de ser identificado. Sua anonimidade reafirma, pelo menos aparentemente, a pouca relevância que era dada às figuras dos negros enquanto tema para as artes da época. Kate Lowe (2013a), em seu artigo The Lives of African Slaves and People of African Descent in Renaissance Europe (As Vidas dos Escravos Africanos e Pessoas Descendentes de Africanos na Europa Renascentista, tradução nossa), confirma o anonimato deste homem:

O artista também desenhou um segundo africano negro, um homem, ao redor da mesma data. Embora a data de '1508' apareça no desenho, ao lado do monograma de Dürer, ela não é considerada segura. Nada se sabe sobre este homem e pode ser que ele seja um servo ou um empregado do mesmo João Brandão. Dürer escreve que ele o desenhou após 14 de dezembro de 1520 . Com bigode e barba, além do cabelo fechado e crespo, é menos provável que este africano tenha sido um escravo do que Katherina, pois barbas eram geralmente proibidas aos escravos, e sua expressão é menos obviamente desesperada (Lowe, 2013a, p. 17, tradução nossa).

Ainda, outra coisa que nos chamou atenção nesses desenhos de Albrecht Dürer é como ele se afasta da representação humana das faces do medieval tardio, algo pouco usual para ele. Dürer, em várias de suas gravuras, mantinha-se, ainda, muito próximo das formas de desenhar dos artistas medievais. As faces das pessoas negras desenhadas por ele são representações bem próximas da realidade. Essa realidade expressiva dessas pessoas não pode ser notada nas obras mais tradicionais deste artista, como em Der Zeichner des liegenden Weibes, executada na mesma época.

A segunda obra que gostaríamos de analisar aqui é Cabeça de um Homem Negro (Figura 2), de Rubens. Peter Paul Rubens foi um pintor flamengo que trabalhou dentro do estilo barroco. Tal peça de arte foi executada a óleo sobre madeira, e tem como dimensões 35,5 x 25,5 cm.

A pintura foi confeccionada entre 1620 e 1624 . Esse trabalho de Rubens mostra a face de um homem negro que olha tristemente para baixo. Para além desta obra, Peter Paul Rubens executa dois estudos nomeados Estudos da Cabeça de um Homem Negro e Quatro estudos de Cabeças Masculinas. Rubens executa quatro cabeças em cada um desses estudos, bem próximas àquela do modelo de Cabeça de um Homem Negro, mas de vistas e tamanhos distintos.

Podemos observar na pintura Cabeça de um Homem Negro que o tratamento de luz se coloca como tipicamente barroco. A luz entra no ambiente de forma lateral e faz com que Rubens deixe ver mais claridade nas partes mais diretamente afetadas pela luminosidade. Ainda, a pele escura do modelo dá um distinto efeito à luminosidade. Isso pode explicar a utilização de modelos negros, pois a cor da pele exigia dos pintores novas maneiras de se trabalhar com a luz. Isso poderia ser considerado um exercício inovador para ampliar a habilidade do pintor.

690 Educação \& Realidade, Porto Alegre, v. 42, n. 2, p. 687-706, abr./jun. 2017. 
Lembramos que os modelos pintados na época eram, em sua grande maioria, pessoas com a tez branca. Kate Lowe (2013b) informa-nos que: "Rubens estava claramente preparado para retrabalhar e reinterpretar figuras que chamavam sua atenção, quase que independentemente de sua configuração" (Lowe, 2013b, p. 109, tradução nossa).

Figura 2 - Cabeça de um Homem Negro, de Peter Paul Rubens, de 1620-1624, Óleo sobre Madeira, de 35,5 x 25,5cm

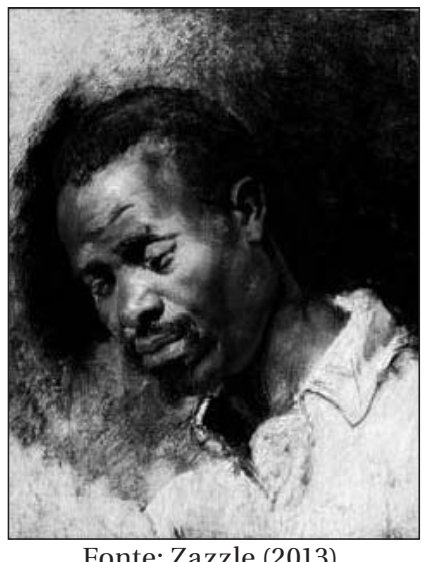

Fonte: Zazzle (2013).

Também, o modelo retratado nos deixa ver seu rosto extremamente triste. Ele está cabisbaixo, porta uma camisa branca e visivelmente um pouco suja. Provavelmente Peter Paul Rubens executou essas pinturas em Antuérpia (Bélgica). Lembramos que o local onde vivia este pintor, Antuérpia, sempre foi uma cidade com um movimentado e importante porto, o que ajudava a ver pessoas de todas as partes do mundo.

Mais um artista que retratou, com frequência, homens negros foi o pintor francês Debret. Jean-Baptiste Debret veio para o Brasil com a missão artística francesa de 1816, a convite do rei D. João VI. Debret se mostrou chocado com a quantidade de escravos negros nas cidades do Brasil, principalmente no Rio de Janeiro.

Pintor com formação da escola de pintura neoclássica francesa, Jean-Baptiste Debret foi registrando as cenas que presenciava no cotidiano das cidades, incluindo os vários ofícios dos negros escravizados. A professora Ana Mae Barbosa (1995) nos conta como aconteceu a vinda dos artistas da missão artística francesa de 1816 ao Brasil; o que encontraram nessas terras e suas consequências:

Para criar a Academia Imperial de Belas-Artes, D. João VI, através do Marquês de Marialva, que se achava na Europa, e do naturalista Alexandre von Humboldt, que estivera no Brasil, contratou artistas que ensinavam no Instituto de França e eram a vanguarda da época. Os artistas deste Instituto, criado e desenvolvido por Napoleão Bonapar- 
te, depois de sua queda passaram a sofrer perseguições e alguns deles, dentre vários convites recebidos para emigrar, inclusive de Catarina da Rússia, aceitaram vir para o Brasil. O ex-diretor da Seção de Belas-Artes do Ministério do Interior de Napoleão, Joachim Lebreton, organizou o grupo. Eram todos neoclássicos convictos e interferiram ostensivamente na mudança de paradigma estético no Brasil. Quando chegaram, encontraram um barroco florescente. Importado de Portugal, o barroco havia sido modificado pela força criadora dos artistas e artífices brasileiros, e podemos dizer que já existia um barroco brasileiro completamente diferente do português, do espanhol e do italiano, muito mais sensual, sedutor e até mais kitsch, se quisermos usar uma designação atual (Barbosa, 1995, p. 60).

Tal choque de padrões artísticos parece não ter influenciado muito as obras que Debret produziu no Brasil. Suas aquarelas, desenhos e pinturas executados aqui, deixam-nos perceber uma influência claramente neoclássica, mas não somente restrita aos padrões desse estilo. Jean-Baptiste Debret encontra sua verdadeira forma expressiva ao pintar e desenhar nestas paragens brasileiras. Ele representou nossos tipos humanos, nossa flora, nossa fauna e nosso cotidiano.

Ainda, Jean-Baptiste Debret retratava, geralmente, os negros escravizados executando seus trabalhos e ofícios. Somente conhecemos alguns detalhes imagéticos da vida brasileira da primeira metade do século XIX através de várias obras deixadas por Debret. Esse artista, para além de mostrar os negros em seus afazeres, também desejou detalhar os escravos enquanto tipos humanos, representando as várias nações de origem africana, como vemos no trabalho intitulado Diferentes $\mathrm{Na}$ ções Negras (Figura 3):

Figura 3 - Diferentes Nações Negras, de Jean-Baptiste Debret. Gravura.

Cerca de 1830. Na imagem identificam-se as seguintes etnias: 1Monjolo; 2- Mina; 3, 4, 8 e 9- Moçambique; 5 e 6- Benguela; e 7- Calava

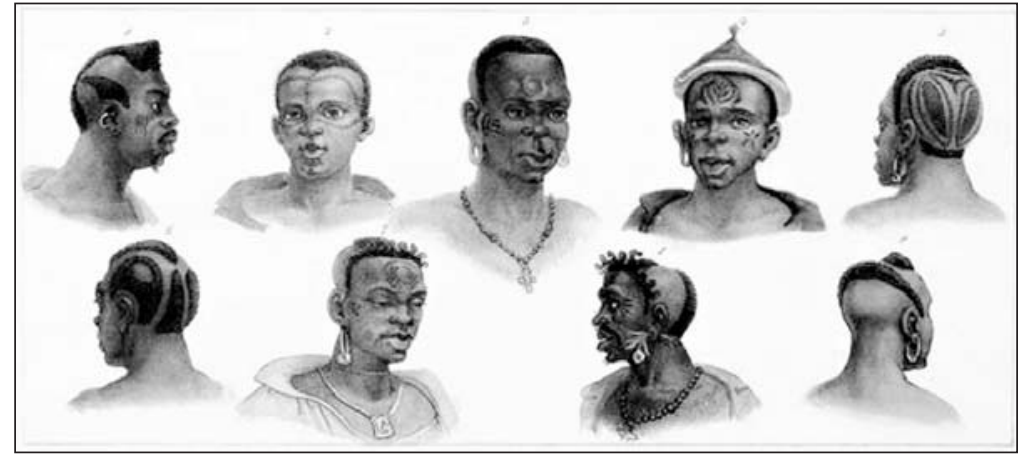

Fonte: Wikipédia (2008).

Recordamos aos leitores que a economia brasileira do século XIX era baseada no sistema escravocrata. Os homens negros foram violen- 
tamente retirados de suas terras de origem e inseridos no cruel sistema escravocrata brasileiro, devendo servir a seus senhores brancos ou serem severamente castigados. A absurda necessidade de grandes quantidades de escravos negros para que a vida do Brasil Império funcionasse foi algo que surpreendeu a Debret. Colocamos uma passagem de Wlamyra de Albuquerque e Walter Fraga Filho (2006, p. 66-68) em relação à escravidão no Brasil:

A escravidão foi muito mais do que um sistema econômico. Ela moldou condutas, definiu desigualdades sociais e raciais, forjou sentimentos, valores e etiquetas de mando e obediência. A partir dela instituíram-se os lugares que os indivíduos deveriam ocupar na sociedade, quem mandava e quem devia obedecer. Os cativos representavam o grupo mais oprimido da sociedade, pois eram impossibilitados legalmente de firmar contratos, dispor de suas vidas e possuir bens, testemunhar em processos judiciais contra pessoas livres, escolher trabalho e empregador.

Podemos inferir que havia uma necessidade de registrar as várias nações de escravos negros no Brasil, pois não somente Debret faz esse tipo de registros. Parecia haver uma necessidade de conhecimento e reconhecimento das nações africanas e dos estereótipos ligados a cada nação. Notemos as imagens de escravos negros: todos os homens, revelando seus penteados étnicos e suas pinturas corporais, mostrando, claramente, que eram seres humanos culturalmente diferentes e que vinham de lugares distintos. Debret nos deixa ver, ainda, as bijuterias destes homens e a suas escarificações ${ }^{2}$.

Essas gravuras de rostos agrupados pareciam ter uma função muito além da artística, pois nos deixa ver que havia uma necessidade de diferenciação, de separação, de exclusão. Lembramos que os comerciantes de negros diferenciavam as nações e as ligavam a certos afazeres, o que as valorizavam ou depreciavam em relação ao valor de mercado. Ainda, era uma época em que o Brasil começava a definir sua identidade, a se constituir enquanto nação e a estabelecer instituições. Nesse momento, registrar todos os tipos humanos que viviam aqui parecia ser um ponto relevante para os vários artistas europeus que trabalhavam no Brasil.

Sabemos que os artistas europeus da Missão Francesa de 1816 desejavam registrar nossa dependência econômica do trabalho dos negros escravizados. Jean-Baptiste Debret deixou isso óbvio na variedade e quantidade de obras que executou com os temas dos vários ofícios dos escravos. Vale ressaltar que, no Brasil Colônia e Império, um homem negro, forte e sadio valia mais como escravo do que uma criança ou uma mulher negra, conforme a seguinte passagem de Wlamyra de Albuquerque e Walter Fraga Filho (2006, p. 54):

Uma vez escolhido o escravo ou escrava, vendedor e comprador discutiam preços e condições de venda. Caso não tivesse doenças, o homem adulto normalmente era vendido por preço mais alto do que mulheres e crianças meno- 
res de dez anos. Os fazendeiros que compravam todo um 'lote' de escravos muitas vezes empenhavam colheitas futuras de café ou açúcar para pagá-los.

Outro artista que nos interessa para este artigo é Rugendas. Da mesma forma que Debret, Johann Moritz Rugendas parecia muito preocupado em mostrar os trabalhos dos negros em suas obras artísticas. Lembramos, também, que Johann Moritz Rugendas também desenhou e pintou paisagens bucólicas e perdidas, desejando dar um ar romântico à vida selvagem dos trópicos brasileiros. Ainda, ele executou um largo registro de tipos humanos de indígenas e escravos no Brasil. O trabalho de Rugendas a seguir (Figura 4) é uma gravura com negros provenientes de Moçambique, intitulada Mozambique, mostrando cinco cabeças de homens.

Podemos ver as escarificações, como na gravura de Jean-Baptiste Debret, a centralidade do homem com o maior número de marcas étnicas faciais e a disposição de um conjunto de cabeças formando um X. Tal arranjo nos faz lembrar as imagens detalhadas de diferentes grupos étnicos indígenas. Cremos que tais imagens e arranjos pareciam servir para identificar as representações dos diferentes.

Tanto Rugendas quanto Debret selecionaram pessoas com especificidades muito distintivas para serem representados. Notamos que há um específico interesse de Rugendas pelas escarificações faciais, marcas que ajudariam a identificar as pessoas através de suas nações étnicas da África.

Percebemos, também, que grande variedade de imagens de homens negros nas artes visuais está diretamente ligada à servidão ou à escravidão. O biótipo negro era visto, pelos europeus, como bastante exótico para ser pintado e desenhado, seja pela luminosidade dos tons de pele negra ou por traços faciais particulares. No caso brasileiro, o homem negro foi retratado como um escravo em seu ofício ou por ser pertencente a etnias africanas distintas.

Tais artistas executaram, ao retratar os negros escravizados, quase que um trabalho etnográfico, registrando os costumes da época. Lembramos que tudo o que deixamos ver neste parágrafo se refere aos artistas aqui selecionados e ao período temporal que vai do século XV até a primeira metade do século XIX. Utilizamo-nos de uma passagem de Reginaldo Prandi (2000, p. 52) sobre este ponto específico:

Entre os anos de 1525 e 1851, mais de cinco milhões de africanos foram trazidos para o Brasil na condição de escravos, não estando incluídos neste número, que é uma aproximação, aqueles que morreram ainda em solo africano, vitimados pela violência da caça escravista, nem os que pereceram na travessia oceânica. Não se sabe quantos foram trazidos desde que o tráfico se tornou ilegal. Ao longo de mais de três séculos, enquanto a própria nação brasileira se formava e tomava corpo, os africanos foram trazidos das mais diferentes partes do continente africano abaixo do Saara. 
Figura 4 - Mozambique. Gravura. Cerca de 1822

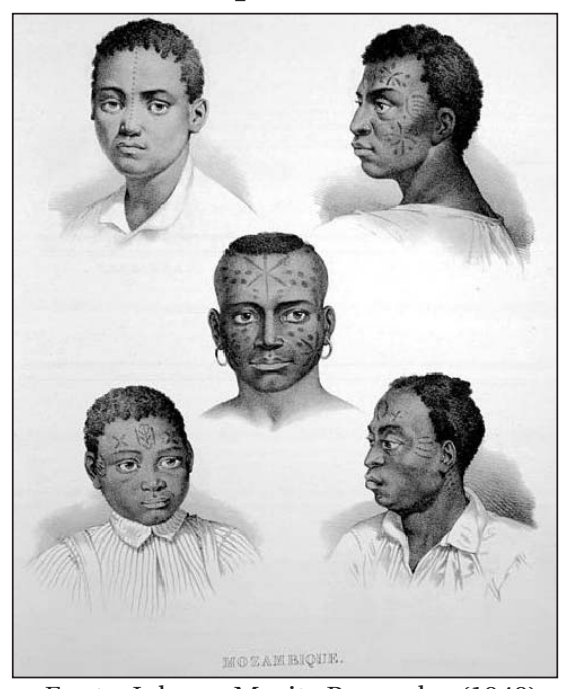

Fonte: Johann Moritz Rugendas (1949).

Depois de tudo que foi colocado, podemos ver que a escravidão e a servidão marcaram, por um período longo, as representações em imagens dos homens negros. Verificamos, portanto, que a linguagem visual mais frequente na representação dos homens negros (seja no desenho, na pintura e nas gravuras), revelava significados sobre esses homens como: tipos exóticos, pessoas para servirem ao branco europeu, seres humanos de segunda classe etc.

Devemos lembrar que as imagens podem ter as mais variadas e possíveis significações. Se as analisamos de acordo com os pensamentos de Stuart Hall (2009), entendemos que as significações das imagens estão em constante mudança. Também, as imagens, sejam quais forem, demandam respostas da audiência, revelando-nos as múltiplas leituras pessoais que podem ser feitas de tais imagens.

Neste texto, portanto, deixamos nossas impressões das imagens selecionadas e buscamos trabalhar com o que elas nos trazem, tentando dar significações a elas. Uma leitura dessas imagens que revele uma ligação com o exótico, com a escravidão e com a servidão parece não ser nada novo, no entanto, o que nos impulsionou, neste escrito, foi desvendar uma linha de pensamento imagético que estivesse ligada a todas as obras aqui estudadas, todas elas com fortes rostos de homens negros.

Essa escolha por analisar obras com rostos negros masculinos não foi aleatória, mas proposital, pois o rosto funciona (hoje mais que nunca, vide as barreiras eletrônicas de controle de passaportes e fronteiras) como instrumento de reconhecimento da pessoa. Por que ainda temos que tirar fotos do rosto (mesmo que sejam eletrônicas) para documentos? O rosto mostra nossa fisionomia, nossa aparência, nosso semblante, nosso aspecto, enfim, nossa presença. 
Também, podemos pensar sobre a escravidão como uma manipulação da masculinidade dos homens negros. Isso com a intenção de degradar não somente os corpos masculinos escravizados, mas estereotipando os negros negativamente. Essa fórmula de estereotipificação dos negros escravos, no Brasil, como preguiçosos foi desenvolvida pelo professor Walace Rodrigues no artigo A 'Ladeira da Preguiça' e o Estereótipo Histórico da Preguiça dos Negros (Rodrigues, 2014).

Ainda, podemos dizer que todo homem branco e poderoso do período da escravidão queria possuir um grande número de escravos homens. Isso lhe dava mão de obra para trabalhar em seus negócios agrícolas e status (representação social) de poder.

Contudo, os escravos negros, que sempre foram incansáveis trabalhadores, não foram completamente passivos à escravidão, pois houve várias revoltas, inúmeras fugas, várias lutas e muita resistência por parte dos escravos. Compreendemos, assim, que havia uma forte relação de poder que se utilizava das masculinidades enquanto ações com fortes significações sociais. Os senhores de escravos, homens de formação eurocêntrica e brancos, com suas masculinidades hegemônicas tentavam, de qualquer forma, subordinar os homens negros escravizados.

Esse conceito de masculinidade hegemônica é usado por vários estudiosos e de formas distintas. Ele pode caber neste texto, posto que o negro escravizado tinha seu corpo submetido às mais variadas vontades dos homens brancos, seus proprietários e senhores. Acerca do conceito de masculinidade hegemônica, Robert Connell e James Messerschmidt (2013, p. 241-242) nos mostram que:

O conceito de masculinidade hegemônica formulado há duas décadas influenciou consideravelmente o pensamento atual sobre homens, gênero e hierarquia social. Esse conceito possibilitou uma ligação entre o campo em crescimento dos estudos sobre homens (também conhecidos como estudos de masculinidade e estudos críticos dos homens), ansiedades populares sobre homens e meninos, posição feminista sobre o patriarcado e modelos sociais de gênero. Encontrou uso em campos aplicados que variam desde a educação ao trabalho antiviolência até a saúde e o aconselhamento.

Assim, o corpo do homem negro funcionou não apenas como símbolo de posses e poder social, mas também a masculinidade desses escravos deveria ser dominada. Os senhores desejavam corpos dóceis e submissos. Isso demonstra uma clara relação desigual de poder. Por conseguinte, não podemos nos admirar que as representações imagéticas dos rostos de negros escravos fossem sempre tristes e que tivessem uma função tão irrelevante nas artes visuais do período analisado, posto que os negros fossem colocados como temas não dignos de serem representados pelas artes do Ocidente.

Também, focando nossa atenção na desconstrução dos discursos da diferença que vemos nas representações dos artistas selecionados, podemos usar tais imagens em nossa prática pedagógica. A professora 
Eliane dos Santos Cavalleiro (2005) mostra-nos a relevância em levantar temas ligados às diferenças dentro do ambiente escolar, principalmente quanto se refere ao racismo:

\begin{abstract}
Na educação brasileira, a ausência de uma reflexão sobre as relações raciais no planejamento escolar tem impedido a promoção de relações interpessoais respeitáveis e igualitárias entre os agentes sociais que integram o cotidiano da escola. O silêncio sobre o racismo, o preconceito e a discriminação raciais nas diversas instituições educacionais contribui para que as diferenças de fenótipo entre negros e brancos sejam entendidas como desigualdades naturais. Mais do que isso, reproduzem ou constroem os negros como sinônimos de seres inferiores. O silêncio escolar sobre o racismo cotidiano não só impede o florescimento do potencial intelectual de milhares de mentes brilhantes nas escolas brasileiras, tanto de alunos negros quanto de brancos, como também nos embrutece ao longo de nossas vidas, impedindo-nos de sermos seres realmente livres 'para ser o que for e ser tudo' - livres dos preconceitos, dos estereótipos, dos estigmas, entre outros males. Portanto, como professores(as) ou cidadãos(ãs) comuns, não podemos mais nos silenciar diante do crime de racismo no cotidiano escolar, em especial se desejamos realmente ser considerados educadores e ser sujeitos de nossa própria história (Cavalleiro, 2005, p. 11-12).
\end{abstract}

É pensando sempre em não nos silenciarmos diante da discriminação e mostrar a todos os nossos alunos as grandes riquezas que o conhecimento do outro pode nos aportar é que este escrito busca trabalhar com imagens de negros. Há que se perguntar aos estudantes: $\mathrm{O}$ que vocês acham dessas imagens? O que vocês veem nessas imagens? Por que vocês acham que o artista escolheu representar homens e negros? Por que o artista somente pintou/desenhou cabeças? Entre várias outras indagações que ajudem a instigar respostas e a mostrar vias para que o professor explore os discursos por trás das imagens e vá desconstruindo tais discursos.

Ainda, partindo desse conjunto de exemplos imagéticos, os professores podem apontar para representações do presente, para as imagens que são veiculadas hoje. Por exemplo, empregadas domésticas negras nos filmes e nas telenovelas; homens negros bem-sucedidos mostrados somente como cantores e jogadores de futebol, nunca médicos, professores ou advogados, entre outros exemplos.

Muito se pode construir em discussões sobre racismo e preconceito dentro da sala de aula. Tais discussões devem levar a ações e ajudar a tornar as crianças cada vez mais críticas e a aceitarem as pessoas da maneira como são. Assim sendo, Fabiana Moraes (2013) faz-nos recordar que a instituição escolar é o perfeito espaço para discutir sobre a aceitação do outro, principalmente por causa dos diferentes fenótipos encontrados nas salas de aula das escolas brasileiras: 
Desconstruindo Discursos de Diferença na Escola

[...] o lócus privilegiado para emergência de embates a respeito da cor, porque ali se encontram crianças e adolescentes pertencentes a diferentes grupos fenotípicos. Essa heterogeneidade é refletida, não raro, na própria dificuldade entre alunos e corpo docente em apontar esta tal variedade para então apreendê-la em 'grupos de cor' mais específicos, como pretos, pardos e brancos. Surgem, neste sentido, novamente as dificuldades de se classificar como sendo de determinada cor, demonstrando como, fortemente no espaço da escola, a cor da pele é uma construção social da qual fazem parte até mesmo o sucesso escolar dos alunos (Moraes, 2013, p. 66).

No caso brasileiro, a compreensão social de quanto mais preto menos chances de ascender socialmente deve ser desmistificada na escola e em casa. Crianças negras e crianças brancas devem aprender que estão inseridas em um sistema social sutil de preconceito de cor criado para favorecer as elites brancas que sempre dominaram o Brasil. Obviamente que isso deve ser feito de acordo com a idade de cada grupo escolar e de maneira inteligente, pois, se racismo é um aprendizado, ele pode ser desaprendido. O sociólogo Oracy Nogueira nos deixa ver que este preconceito em relação aos negros é um preconceito de marca, pois se dá a partir da cor da pele e das preconcepções sociais ligadas a ela:

Considera-se como preconceito racial uma disposição (ou atitude) desfavorável, culturalmente condicionada, em relação aos membros de uma população, aos quais se têm como estigmatizados, seja devido à aparência, seja devido a toda ou parte da ascendência étnica que se lhes atribui ou reconhece. Quando o preconceito de raça se exerce em relação à aparência, isto é, quando toma por pretexto para as suas manifestações os traços físicos do indivíduo, a fisionomia, os gestos, o sotaque, diz-se que é de marca; quando basta a suposição de que o indivíduo descende de certo grupo étnico para que sofra as consequências do preconceito, diz-se que é de origem (Nogueira, 2006, p. 292).

Também, essa percepção comparativa de Oracy Nogueira entre os casos brasileiros e norte-americanos nos faz perceber como nós brasileiros utilizamos determinadas sutilezas sociais para discriminar ou aceitar o outro:

Assim, um clube recreativo, no Brasil, pode opor maior resistência à admissão de um indivíduo de cor que à de um branco; porém, se o indivíduo de cor contrabalançar a desvantagem da cor por uma superioridade inegável, em inteligência ou instrução, em educação, profissão e condição econômica, ou se for hábil, ambicioso e perseverante, poderá levar o clube a lhe dar acesso, 'abrindo-lhe uma exceção', sem se obrigar a proceder da mesma forma com outras pessoas com traços raciais equivalentes ou, mesmo, mais leves. Nos Estados Unidos, ao contrário, as restrições impostas ao grupo negro, em geral, se mantêm, 
independentemente de condições pessoais como a instrução, a ocupação etc. Tanto a um negro portador de $\mathrm{PhD}$ (doutor em filosofia, título altamente respeitado naquele país) como a um operário, será vedado residir fora da área de segregação, recorrer a certos hospitais, frequentar certas casas de diversões, permanecer em certas salas de espera, em estações, aeroportos etc., utilizar-se de certos aposentos sanitários, fontes de água etc., ainda que varie de uma região para outra e, mesmo, de uma localidade para outra, a amplitude de situações em que se impõem restrições (Nogueira, 2006, p. 293).

Obviamente, os exemplos do sociólogo Oracy Nogueira são datados da época de seus escritos (segunda metade do século XX). No entanto, as situações de racismo institucionalizado ainda são vistas no Brasil atual, principalmente nos ambientes frequentados pelas elites.

Retornando à escola, para que tenhamos uma educação que seja verdadeiramente crítica, humanizadora e que (sem distinção) abarque a todos, é imprescindível que os educadores também sejam bem formados e que busquem formação continuada no que se refere aos vários tipos de discriminação que ocorrem dentro no ambiente escolar, pois a escola não pode, de maneira alguma, trabalhar com a naturalização de preconceitos. Cada instituição escolar tem a obrigação de lutar contra todo tipo de intolerância, porém, seus educadores devem compreender, de verdade, a relevância de tal tarefa.

Devemos lembrar que como a intensificação dos debates sobre racismo se deu através das muitas lutas dos vários grupos negros espalhados pelos quatro cantos do país, a Lei de Diretrizes e Bases da Educação - Lei 9.394/96 - (Brasil, 1996) foi alterada pela Lei 10.639 (Brasil, 2003), dando visibilidade à história e à cultura afro-brasileira. A LDB passou a trazer o artigo 26, que nos diz:

Art. 26-A. Nos estabelecimentos de ensino fundamental e médio, oficiais e particulares, torna-se obrigatório o ensino sobre História e Cultura Afro-Brasileira.

$\S 1^{\text {a }}$ - O Conteúdo programático a que se refere o caput deste artigo incluirá o estudo da História da África e dos Africanos, a luta dos negros no Brasil, a cultura negra brasileira e o negro na formação da sociedade nacional, resgatando a contribuição do povo negro nas áreas social, econômica e política pertinentes à História do Brasil.

$\S 2^{\mathrm{a}}$ - Os Conteúdos referentes à História e Cultura Afro-Brasileira serão ministrados no âmbito de todo o currículo escolar, em especial nas áreas de Educação Artística e de Literatura e História Brasileiras.

Art. 79-B. O calendário escolar incluirá o dia 20 de novembro como 'Dia Nacional da Consciência Negra' (Brasil, 2003, art. 26-A; art. 79-B).

A professora Maria José Lopes da Silva (2005) nos deixa ver que uma das alternativas para se trabalhar contra o preconceito e a favor da 
diversidade nas escolas seria através de trabalhos artísticos que dessem valor à cultura afro-brasileira e negra, buscando colocar o foco em artistas negros ou que tematizem a negritude. Conforme pode ser visto na seguinte passagem:

O próprio estudioso francês Roger Bastide, que durante alguns lecionou na USP, assim se pronunciou: 'a arte afro-brasileira é uma arte viva, não estereotipada. Mas na sua evolução até as últimas transformações, ela vem preservando as estruturas tanto mentais como puramente estéticas da África'. No entanto, nos dias atuais, o preconceito dominante ainda vê o artista negro brasileiro como 'primitivo' e 'naïf' (ingenuo); é grande a barreira que o artista plástico negro encontra para impor-se no mercado brasileiro. Cabe aos professores de Artes, então, uma cuidadosa reflexão sobre a forma de estabelecer a ponte entre a cultura do educando e a cultura autodenominada 'universal' (a cultura ocidental imposta). O aluno já vem para a escola com um potencial criativo; a escola não precisa induzi-lo, sua função e trabalhá-lo (Silva, 2005, p. 125-126).

Também, a pesquisadora Eliane dos Santos Cavalleiro (2005) nos mostra a necessidade dos profissionais escolares em trabalhar com temas relacionados às diferenças. Isso ajuda a desconstruir os discursos preconceituosos e as visões estereotipadas sobre o outro. No entanto, como nos diz a professora Cavalleiro, sem o auxílio de um material didático-pedagógico específico e sem o completo envolvimento da comunidade, as ações contra o preconceito e a discriminação se tornam difíceis:

[...] nós, educadores(as) brasileiros(as), necessitamos urgentemente contemplar no interior das escolas a discussão acerca das relações raciais no Brasil, bem como de nossa diversidade racial. Nessa linha, é preciso não só boa vontade e sensibilidade dos profissionais da educação, mas também o fornecimento de material didático-pedagógico antirracista e recursos auxiliares aos professores para que possam ministrar aulas combatendo o preconceito e a discriminação raciais (Cavalleiro, 2005, p. 14).

Desta forma, nós sugerimos, neste escrito, o trabalho com imagens variadas de homens negros. Podemos utilizar, ainda, imagens de vários períodos históricos, desde que levantemos as questões adequadas e coerentes para auxiliar em uma educação democrática, não etnocêntrica, livre de preconceitos e que valorize o outro. Isso ajudará muito para que todos sejam incluídos e respeitados.

As escolas não podem continuar a serem lugares que perpetuam as desigualdades sociorraciais, mas elas devem ser espaços onde se ensina que as diferenças são positivas e enriquecedoras. Tal tarefa é difícil, mas não impossível de ser alcançada. Lembremos que as escolas do Brasil seguem um modelo eurocêntrico em relação à educação, o que já começa dificultando a tarefa de desaprender o racismo. Vale mencionar 
uma passagem do militante Abdias do Nascimento citado por Sales Augusto dos Santos (2005, p. 23):

O sistema educacional [brasileiro] é usado como aparelhamento de controle nesta estrutura de discriminação cultural. Em todos os níveis do ensino brasileiro - elementar, secundário, universitário - o elenco das matérias ensinadas, como se executasse o que havia predito a frase de Sílvio Romero ${ }^{3}$, constitui um ritual da formalidade e da ostentação da Europa, e, mais recentemente, dos Estados Unidos. Se consciência é memória e futuro, quando e onde está a memória africana, parte inalienável da consciência brasileira? Onde e quando a história da África, o desenvolvimento de suas culturas e civilizações, as características, do seu povo, foram ou são ensinadas nas escolas brasileiras? Quando há alguma referência ao africano ou negro, é no sentido do afastamento e da alienação da identidade negra. Tampouco na universidade brasileira o mundo negro-africano tem acesso. $\mathrm{O}$ modelo europeu ou norte-americano se repete, e as populações afro-brasileiras são tangidas para longe do chão universitário como gado leproso. Falar em identidade negra numa universidade do país é o mesmo que provocar todas as iras do inferno, e constitui um difícil desafio aos raros universitários afro-brasileiros.

Desta urgência em compreender nossa complexa sociedade brasileira, com todas as suas especificidades e grupos sociais, parte nosso esforço em tentar educar através de imagens, ações e leituras variadas. Se os rostos de homens negros podem nos incentivar a discutir questões importantes em relação à tolerância no ambiente escolar e ao respeito, então por que não fazê-lo? Francisca Maria do Nascimento Sousa (2005) informa-nos que há muito a ser discutido nas instituições escolares com relação ao racismo e a discriminação enfrentados pelos negros no Brasil:

O fato de, muitas vezes, o racismo não ser explicitado verbalmente, não o torna menos presente e agressivo no dia-a-dia dos alunos e alunas negros(as), pois há muitas outras maneiras pelas quais ele se manifesta na cultura brasileira: privilegiam-se os brancos, reconhece-se este biótipo como aquele que representa a beleza estética e intelectual da raça humana e ainda acha-se normal que este segmento da população detenha o poder político, econômico, cultural e religioso; como se fosse algo natural e não resultado da organização histórica capitalista, discriminatória e excludente da sociedade brasileira. É comum ainda, no nosso país, não se querer discutir as discriminações, especialmente a racial. Dizem até que falar de racismo é invenção de negro complexado, que tem vergonha da própria origem. Felizmente esta cultura do silenciamento está sendo superada, um resultado de décadas de lutas do movimento negro organizado por todo este país e que vem obtendo importantes conquistas, inclusive no campo legal (Sousa, 2005, p. 110). 
Portanto, podemos verificar que a valorização das diferenças e da diversidade no Brasil deve ser amplamente abordada no ambiente escolar, sempre visando desconstruir preconceitos e enfraquecer a intolerância em relação aos afro-brasileiros. As aulas de Artes, História, Língua Portuguesa, Geografia, entre tantas outras disciplinas, têm que incorporar os mais variados temas transversais importantes para nossa sociedade (entre eles a luta contra o racismo e o preconceito) para que nossas crianças e jovens formem um senso claro da importância da diversidade cultural de nosso país e da relevância de cada pessoa (sem importar cor da pele, nível social, gênero etc.) para a construção de um país mais justo e igualitário.

\title{
Considerações Finais
}

Depois da análise de obras de cabeças de homens negros apresentadas, podemos dizer que Albrecht Dürer desejava representar um negro pela singularidade deste modelo em relação a outros que costumava desenhar (geralmente modelos brancos); Peter Paul Rubens deixa-nos ver um exercício com cor a partir da pintura de vários rostos negros; Jean-Baptiste Debret desenha e pinta os homens negros para deixar registradas informações do cotidiano, dos costumes, as formas de vida e as várias nações étnicas no Brasil; e Johann Rugendas busca entender como diferentes grupos étnicos, com suas características tão próprias, colocavam-se na sociedade da época, no Brasil.

Também, podemos dizer que o poder subjugador de um homem sobre o outro é algo temporário, pois papéis mudam com frequência (como nos mostra a história) e situações de opressão se tornam situações de força e de esclarecimento. Um desses caminhos pode ser pela via da educação, fazendo com que uma pessoa deixe de ser coisa e passe a ser um ser pensante e libertário, como nos informa Paulo Freire (1997, p. 9):

\begin{abstract}
Não pode existir uma teoria pedagógica, que implica em fins e meios da ação educativa, que esteja isenta de um conceito de homem e de mundo. Não há, nesse sentido, uma educação neutra. Se, para uns, o homem é um ser da adaptação ao mundo (tomando-se o mundo não apenas em sentido natural, mas estrutural, histórico-cultural), sua ação educativa, seus métodos, seus objetivos, adequar-se-ão a essa concepção. Se, para outros, o homem é um ser de transformação do mundo, seu que fazer educativo segue um outro caminho. Se o encaramos como uma 'coisa', nossa ação educativa se processa em termos mecanicistas, do que resulta uma cada vez maior domesticação do homem. Se o encaramos como pessoa, nosso que fazer será cada vez mais libertador.
\end{abstract}

Dessa forma, masculinidades hegemônicas se colocam como configurações sociais mutantes, instáveis e temporárias. E isso pode ser falado e pensado dentro das escolas, para ajudar na desconstrução de estereótipos em relação aos afro-brasileiros e negros, tomando as re- 
presentações imagéticas colocadas como ponto de partida para alavancar a desconstrução de discursos tidos como hegemônicos.

Há que se superar essa cultura do silenciamento em relação ao racismo e ao preconceito em nosso país, pois nossa grande riqueza está na diferença e no aporte que cada um pode dar à sociedade. A exclusão somente funciona (negativamente) como mecanismo social de poder, mas não agrega nada à vida das pessoas, ao contrário, nos paralisa numa mentalidade ainda ultrapassada e escravocrata.

A utilização das imagens de negros, enquanto representações históricas do preconceito, devem ser feitas no campo da educação. Isso porque tais imagens são possibilitadoras de descobertas e indagações que podem instigar a desconstrução dos discursos de cor construídos no Brasil.

Além disso, o reconhecimento da escola enquanto lugar de socialização e de desconstrução de preconceitos deve fazer com que as crianças compreendam que a cor de sua pele não é fator determinante de nada. Isso pode ficar claro se utilizarmos os exemplos dados pela história da arte na escola.

Também, poucos são os professores negros dentro das escolas públicas, mesmo aquelas nos confins do Brasil, mas a luta pela igualdade de oportunidades deve ser uma constante no ambiente escolar, podendo ser a arte um desses instrumentos de luta por uma sociedade mais igualitária para todos. A criança deve ter a possibilidade de se ver um futuro professor, um futuro advogado, um futuro médico etc.

Como tornamos as escolas em lugares inclusivos das diferenças? Ações pela via dos próprios conteúdos pode ser uma resposta para auxiliar nesse caminho. Talvez, com projetos pela via das artes visuais seja um dos mais completos meios de inserir a diferença nas vidas dos estudantes.

Também, precisamos descobrir o mundo dentro de nós. Há muito a aprender sobre os outros e sobre nós mesmos. Todos nós crescemos em diferentes famílias, culturas e estruturas sociais e isso faz de cada um de nós um especialista em como lidamos com o mundo que nos rodeia. Nos tornamos inseguros quando confrontados com diferentes opiniões, hábitos e comportamentos, sem entender que novas descobertas podem nos trazer ricos conhecimentos e nos ajudar a nos livrarmos de nossos preconceitos.

Assim, entender o significado da diversidade é reconhecer o fato de que cada ser humano é único e tem uma perspectiva única de ver o mundo e de funcionar nele. Criar espaços com respeito e abertura para as diferentes perspectivas de mundo nos dá uma visão mais ampla de nossa própria cultura e de como podemos fazer as coisas de muitas maneiras diferentes.

Finalizando, sendo o discurso um instrumento de batalhas ideológicas e significativas, cabe à escola a importante função de decifrá-lo historicamente e desconstruí-lo, informando a seus estudantes, através 
da arte e de outros dispositivos, sobre as forças que se articulam em nossa sociedade para gerarem estereótipos, preconceitos e para marcarem diferenças.

Recebido em 21 de julho de 2015 Aprovado em 11 de novembro de 2016

\section{Notas}

1 Desejamos mostrar a diferenciação entre os vocábulos negroe afrodescendente. Neste escrito, utilizamos a definição negro como uma identidade social de luta, levando em conta, muito mais do que a cor da pele, mas uma visão política. O vocábulo afrodescendente começa a cair em desuso, porém se colocou como um termo de inclusão, pois a maioria dos brasileiros somos descendentes de africanos.

2 As escarificações são marcas deixadas pela cicatrização de cortes na pele. Essas marcas são culturais e identificam os mais diferentes grupos étnicos da África negra. Algumas são, ainda hoje, executadas. O corpo toma lugar de objeto social e étnico, identificando a situação da pessoa dentro de seu grupo.

3 A frase de Sílvio Romero é: "Nós temos a África em nossas cozinhas, América em nossas selvas, e Europa em nossas salas de visitas” (Romero, 1980).

\section{Referências}

ALBUQUERQUE, Wlamyra de; FRAGA FILHO, Walter. Uma História do Negro no Brasil. Salvador: Centro de Estudos Afro-Orientais; Fundação Cultural Palmares, 2006.

BARBOSA, Ana Mae. Arte-Educação Pós-Colonialista no Brasil: aprendizagem triangular. Comunicação \& Educação, São Paulo, n. 2, p. 59-64, jan./abr. 1995.

BERGER, Mirela. Falando de Alteridade: olhando o outro, percebendo-se a si mesmo. Material didático desenvolvido pela autora, 2007. Disponível em: $<$ http://www.mirelaberger.com.br/mirela/download/Default.aspx $>$. Acesso em: 15 fev. 2015.

BRASIL. Ministério da Educação. Lei no 10.639 de 9 de janeiro de 2003. Altera a Lei no 9.394, de 20 de dezembro de 1996, que estabelece as diretrizes e bases da educação nacional, para incluir no currículo oficial da Rede de Ensino a obrigatoriedade da temática 'História e Cultura Afro-Brasileira', e dá outras providências. Diário Oficial da União, Brasília, 10 jan. 2003. P. 1.

BRASIL. Ministério da Educação. Lei no 9.394 de 20 de dezembro de 1996. Estabelece as diretrizes e bases da educação nacional. Diário Oficial da União, Brasília, 23 dez. 1996. P. 27833.

CAVALLEIRO, Eliane dos Santos. Introdução. In: BRASIL. Educação Anti-Racista: caminhos abertos pela lei federal no 10.639/03. Brasília: Ministério da Educação; Secretaria de Educação Continuada, Alfabetização e Diversidade, 2005. P. 11-20.

CONNELL, Robert; MESSERSCHMIDT, James. Masculinidade Hegemônica: repensando o conceito. Estudos Feministas, Florianópolis, v. 21, n. 1, p. 241-282, jan./abr. 2013.

FREIRE, Paulo. Papel da Educação na Humanização. Revista da FAEEBA, Salvador, Faculdade de Educação do Estado da Bahia, v. 6, n. 7, p. 9-32, jan./jun. 1997. 
HALL, Stuart. Da Diáspora: identidades e mediações culturais. Belo Horizonte: Editora UFMG, 2009.

LOWE, Kate. The Lives of African Slaves and People of African Descent in Renaissance Europe. In: SPICER, Joaneath. Revealing the African Presence in Renaissance Europe. Baltimore: Walters Art Museum, 2013a. P. 13-34.

LOWE, Kate. Visual Representations of an Elite: african ambassadors and rulers in renaissance europe. In: SPICER, Joaneath. Revealing the African Presence in Renaissance Europe. Baltimore: Walters Art Museum, 2013b. P. 99-115.

MORAES, Fabiana. No País do Racismo Institucional: dez anos de ações do GT racismo no MPPE. Coordenação Assessoria Ministerial de Comunicação Social do MPPE, Grupo de Trabalho sobre Discriminação Racial do MPPE - GT Racismo. Recife: Procuradoria Geral de Justiça, 2013.

NOGUEIRA, Oracy. Preconceito Racial de Marca e Preconceito Racial de Origem: sugestão de um quadro de referência para a interpretação do material sobre relações raciais no Brasil. Tempo Social, São Paulo, v. 19, n. 1, p. 287-308, nov. 2006.

PRANDI, Reginaldo. De Africano a Afro-Brasileiro: etnia, identidade, religião. Revista USP, São Paulo, n. 46, p. 52-65, jun./ago. 2000.

RODRIGUES, Walace. A 'Ladeira da Preguiça' e o Estereótipo Histórico da Preguiça dos Negros. In: IV Congresso Internacional de História. Anais... UFG, Jataí-GO, 23 a 25/set., 2014. Disponível em: <http://www.congressohistoriajatai. org/2014/>. Acesso em: 18 fev. 2014.

ROMERO, Sílvio. História da Literatura Brasileira. 7. ed. Rio de Janeiro: Livraria José Olympio Editora; Brasília: Instituto Nacional do Livro, 1980.

RUGENDAS, Johann Moritz. Viagem Pitoresca através do Brasil. São Paulo: Martins Fontes, 1949

SANTOS, Sales Augusto dos. A Lei no 10.639/03 como Fruto da Luta Anti-Racista do Movimento Negro. In: BRASIL. Educação Anti-Racista: caminhos abertos pela lei federal no 10.639/03. Brasília: Ministério da Educação; Secretaria de Educação Continuada, Alfabetização e Diversidade, 2005. P. 21-38.

SILVA, Maria José Lopes. As Artes e a Diversidade Étnico-Cultural na Escola Básica. In: MUNANGA, Kabengele (Org.). Superando o Racismo na Escola. 2. ed. Brasília: Ministério da Educação; Secretaria de Educação Continuada, Alfabetização e Diversidade, 2005. P. 125-142.

SOUSA, Francisca Maria do Nascimento. Linguagens Escolares e Reprodução do Preconceito. In: BRASIL. Educação Anti-Racista: caminhos abertos pela lei federal no 10.639/03. Brasília: Ministério da Educação; Secretaria de Educação Continuada, Alfabetização e Diversidade, 2005. P. 105-120.

SPICER, Joaneath Ann. Revealing the African Presence in Renaissance Europe. Baltimore: Walters Art Museum, 2013.

WIKIPÉDIA. Ficheiro: Debret - diferentes nações negras. Online, 2008. Disponível em: <https://upload.wikimedia.org/wikipedia/commons/b/bc/Debret_-_Diferentes_Nacoes_Negras.jpg>. Acesso em: 18 fev. 2014.

ZAZZLE. Pôster. Cabeça de um Negro por Rubens. Online, 2013. Disponível em: <https://www.zazzle.com.br/cabeca_de_um_negro_por_rubens_poster-228214786738523392>. Acesso em: 18 fev. 2014. 
Walace Rodrigues é doutor em Humanidades, mestre em Estudos Latino-Americanos e Ameríndios e mestre em História da Arte Moderna e Contemporânea pela Universiteit Leiden (Países Baixos). Pós-graduado (lato sensu) em Educação Infantil pelo Centro Universitário Barão de Mauá - SP. Licenciado pleno em Educação Artística pela UERJ e Licenciado em Pedagogia pela FIC-SP. Professor da Universidade Federal do Tocantins (UFT). E-mail: walacewalace@hotmail.com 